\title{
Developing community partnerships for primary healthcare: An integrative review on management challenges
}

\section{Odete Maria Azevedo Alves, Joaquim Paulo Moreira \& Paula Clara Santos}

To cite this article: Odete Maria Azevedo Alves, Joaquim Paulo Moreira \& Paula Clara Santos (2020): Developing community partnerships for primary healthcare: An integrative review on management challenges, International Journal of Healthcare Management, DOI: $\underline{10.1080 / 20479700.2020 .1723882}$

To link to this article: https://doi.org/10.1080/20479700.2020.1723882

\section{Published online: 24 Feb 2020.}

Submit your article to this journal 지

Џll Article views: 67

Q View related articles $₫$

View Crossmark data ¿ 


\title{
Developing community partnerships for primary healthcare: An integrative review on management challenges
}

\author{
Odete Maria Azevedo Alves (D) ${ }^{\mathrm{a}, \mathrm{b}}$, Joaquim Paulo Moreira (1D) ${ }^{\mathrm{c}, \mathrm{d}, \mathrm{e}}$ and Paula Clara Santos (D) ${ }^{\mathrm{f}, \mathrm{g}, \mathrm{h}}$ \\ ${ }^{a}$ Institute of Biometic Sciences Abel Salazar (ICBAS), University of Porto, Porto, Portugal; ${ }^{b}$ Alto Minho Local Health Unit, Public Business \\ Entity, Viana do Castelo, Portugal; 'Center for Administration and Public Policy (CAPP), University of Lisbon, Lisbon, Portugal; ${ }^{\mathrm{d}}$ Atlantic, \\ Lisboa, Portugal; ${ }^{\mathrm{e}}$ Fernando Pessoa University, Porto, Portugal; ${ }^{\mathrm{f}}$ School of Health, Polytechnic of Porto, Porto, Portugal; ${ }^{9}$ Research Centre in \\ Physical Activity, Health and Leisure (CIAFEL), Faculty of Sport, University of Porto, Porto, Portugal; ${ }^{\text {h}}$ Center for Rehabilitation Research (CIR), \\ Polytechnic of Porto, Porto, Portugal
}

\begin{abstract}
Objectives: The aim of this review was to identify healthcare management barriers, challenges and obstacles in the development of health partnerships in community intervention projects. Methods: We conducted an integrative review using the following data sources: PubMed, B-on, Medline and EBSCOhost. The keywords in the search were: Health Partnerships AND Community Health AND Primary Health Care. We grouped results based on six categories: Environment; Membership; Process and structure; Purpose; Communication; Resources.

Findings: The search conducted identified 844 articles. After being submitted to the first filter and applying the exclusion and inclusion criteria, a total of 56 were reviewed. Of these, 44 dealt with aspects relating to Environment. In 53 articles it was referred that the relationship partners were key to the development of partnerships. Factors relating to the process of collaboration were found in 45 , while factors related to structural elements were mentioned in 40 articles. 31 identified factors relating to purpose. Communication was highly discussed, appearing in 34 articles. Factors relating to resources were given great importance in the literature, appearing in 48 . In 23, the subject of leadership.

Conclusions: The literature reviewed highlighted that dimensions such as relationships, commitment, communication, funding, and structure are key in the long-term sustainability of the partnership. However, more studies are needed.
\end{abstract}

\section{ARTICLE HISTORY}

Received 3 September 2019 Accepted 7 January 2020

\section{KEYWORDS}

Partnerships; community intervention; primary healthcare; integrative review; management challenges

\section{Background}

The growing scarcity of resources dedicated to local healthcare characterizes the current economic and social context of most communities in the world. Based on the difficulties that health services feel in terms of human and material resources, ensuring the economic and financial future of national health systems becomes a key challenge [1].

For the success of prevention programs, it is fundamental to establish community partnerships to foster synergies between institutions and between the limited resources. Community involvement in partnerships is increasingly accepted as best practice in community intervention projects, despite the many barriers or difficulties in doing so [2].

The interest in community partnerships arises mainly in the last two decades of the twentieth century. The growing interest is related to the search for strategies to overcome the difficulties of implementation of incentives for citizen participation, and as a way to overcome some of the difficulties of providing systems service, both in healthcare and social care [3-5].
Therefore, the aim of this study is to identify barriers, obstacles, difficulties, and challenges in developing partnerships in community intervention for health and social care, and contribute to generating new knowledge about establishing partnerships that are more effective.

\section{Methods}

The integrative literature review on health partnerships in community intervention projects was conducted from January through September of 2016. We applied the search in PubMed, B-on, Medline and EBSCOhost databases and were searched articles from 1 September 2006 through 2 January 2016. A standard form was used to extract data using the following search terms: Health Partnerships AND Community Health AND Primary Health Care, which are based on the medical terms of National Library of Medicine [6]. We found 844 articles, it was then applied a filter to obtain article with at least one of the keywords (Barriers OR Obstacle OR Difficulties OR Challenges), yielding a total of 225 articles. 


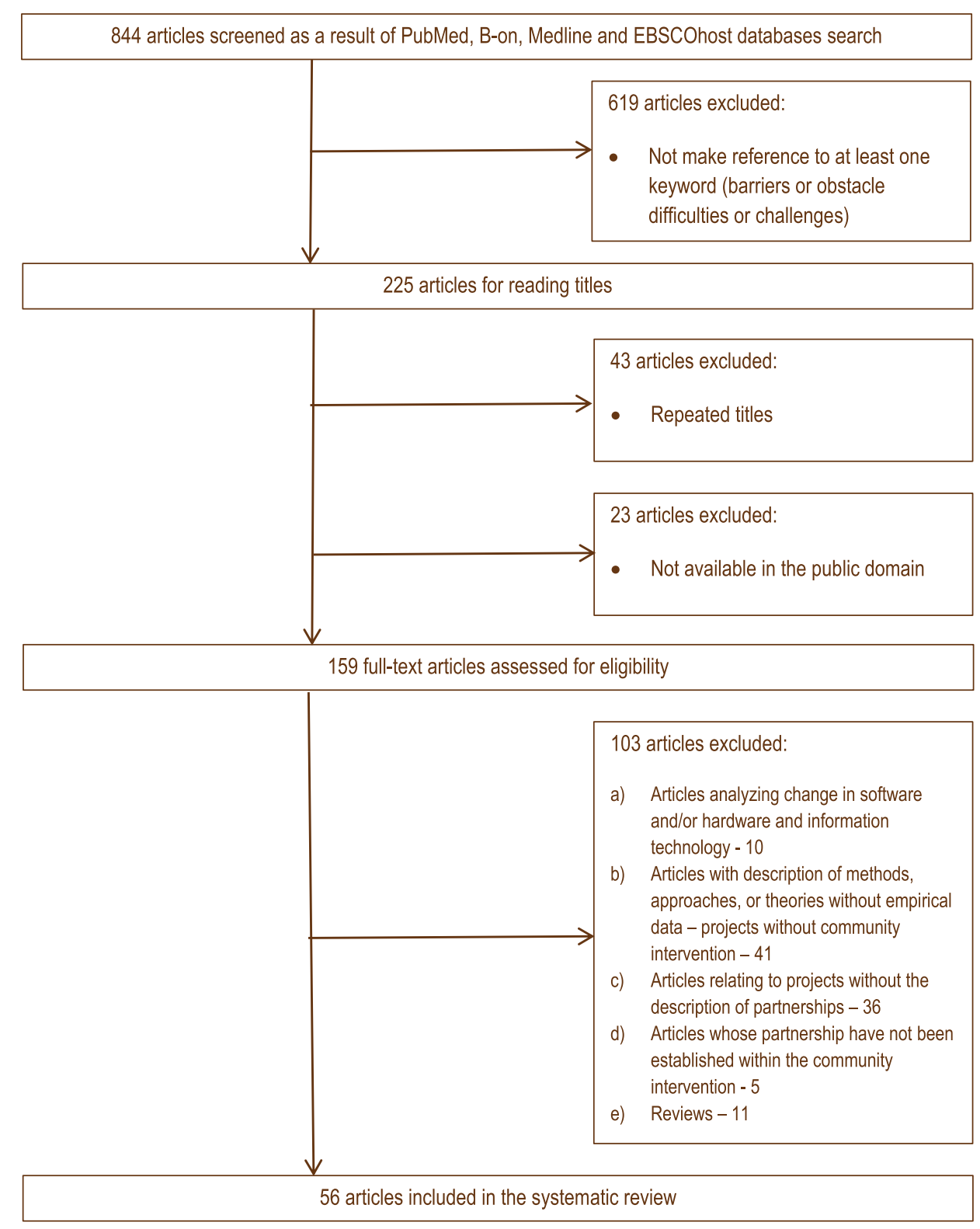

Figure 1. Search strategy [7].

The selection of articles comprehended several steps (Figure 1), according to PRISMA flow methodology [7]. First, we eliminated repeated articles, by reading the title and abstract. In this step 43 articles were excluded by consensus of the reviewers. In the second step, each individual author proceeded to read the paper and selecting those meeting the inclusion criteria (Table 1).

The abstract and application of the inclusion criteria to select studies were considered and authors decided whether or not to obtain the articles full text. However, only 159 articles contained abstract and were published and available in the public domain.

At the consensus meeting, after discussion of the results, 103 articles were eliminated according to exclusion criteria (Table 1). Full publications of all selected abstracts were obtained (in electronic or printed form) All articles were evaluated independently by the reviewers, who selected 56 articles that met all the inclusion criteria (see Appendix for the full list of the 56 selected articles). All articles were assessed independently by the authors. The articles that reunited no consensus were discussed with the authors.

\section{Data collection and content analysis}

A standard form was used for data extraction. This form contained the following variables:

- publication year;

- country;

- method or type of study;

- partners;

- barriers, obstacle, difficulties and challenges in the development of health partnerships

- type of partnership

- study theme 
Table 1. Inclusion and exclusion criteria.

Inclusion
criteria $\begin{aligned} & \text { (a) Make reference to barriers, obstacles, difficulties and } \\ & \text { challenges in developing the community health } \\ & \text { partnerships } \\ & \text { (b) Contain a description of an intervention for the } \\ & \text { development of partnership in community health } \\ & \text { (c) English only } \\ & \text { (d) Publications from the period of } 1 \text { September } 2006 \\ & \text { through } 2 \text { January } 2016 \\ & \text { (e) Being available in full text } \\ & \text { Exclusion } \\ & \text { (a) Articles analyzing change in software and/or } \\ & \text { hardware and information technology } \\ & \text { (b) Articles with description of methods, approaches, or } \\ & \text { theories without empirical data - projects without } \\ & \text { community intervention } \\ & \text { (c) Articles relating to projects without the description } \\ & \text { of partnerships } \\ & \text { (d) Articles whose partnership have not been } \\ & \text { established within the community intervention } \\ & \text { (e) Reviews }\end{aligned}$

According to the research perspective [8], six articles were quantitative studies, namely: one experimental, one quasi-experimental and four descriptive; forty articles were qualitative studies, which of them five were reports and six were case study; and, ten with both, which of them three were case study.

The studies' setting was community intervention in the context of primary health care with the involvement of several stakeholder and community-based organizations of the public, private and third sector, as determined by local needs, including the users, their families and caregivers; community-dwelling; public housing developments; community leaders and community health representatives; healthcare organizations and their workers; social service entities; homecare support services; workplaces, businesses and employers; educational organizations (schools and universities); government (policymakers); local authorities; law enforcement, juvenile justice agencies, consumer advisory/advocacy services, advocacy groups; voluntary sector; non-governmental organizations; faith-based organizations; community associations; representatives from transportation, parks, land use, and urban agriculture; local sports and recreation, community fitness centers, physical therapy, gym; police services; local media outlets; local hotels; among many others to ensure the development, implementation, and sustainability of the interventions.

The analyses of those articles describe the barriers, difficulties and challenges in the development of health partnerships in two countries of North America: United States of America and Canada; in three European countries: UK, Sweden and the Netherlands; in two Oceania countries: Australia and New Zealand; and, also in two Asiatic countries: Taiwan-China and Mongolia. Noteworthy, four articles integrate two or more countries, namely: Australia \& Montana, Australia \& United Kingdom, USA \& Senegal, and Asia-Pacific. Most of the studies were performed in the USA.
Table 2. General characteristics of the articles analysed $(n=$ 56).

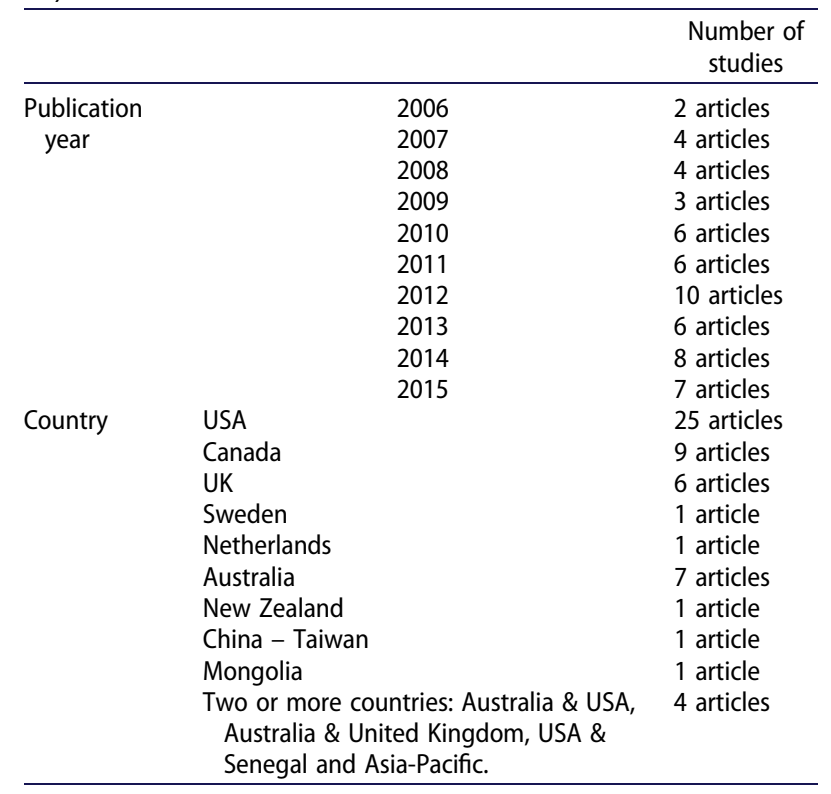

Table 2 summarizes the studies general characteristics (publication year and country).

\section{Results}

The integrative literature review identified a set of barriers, obstacles, difficulties and challenges for the development of health partnerships in community intervention projects. We grouped these results based on the six categories as developed by the Wilder Research Center: (1) Environment; (2) Membership; (3) Process and structure; (4) Communication (5) Purpose; (6) Resources [3,9], which include leadership and power.

In each of these categories, we present the factors that are related to them and that can positively or negatively influence the development of partnerships development and collaboration. Finally, we highlight sustainability, which involves various factors from other categories.

\section{Environment (44 articles)}

We found forty-four articles that dealt with this category, in which we included factors related to community, geography, culture, religious faith and homophily, and politics.

Community related factors were found to be an obstacle or barrier to the development of the partnership. We encountered this in thirty-five articles. The lack of or fragile connection between the partnership and the actual community [10-18] as well as the absence of participation by the community $[10,19,20]$ were highlighted. Factors relating to the actual participants from the community were also found to hinder the development of the partnership [21]. Community 
engagement and/or involvement is essential, as well as the active participation of the partners in all the phases of the process [12,14,17,19,21-37]. The partnership should be community-based. It should have a sense of community and all of its actions should have the community as a base or focus. In turn, the partnership must also be accepted by the community itself $[10,15,18,19,21,23,24,27,33,35-44]$.

Geographical factors such as distance between partners and distance to the facility for participants from the community were also determined to be barriers to the partnership and this was discussed in seven articles [13,15,44-48].

Twelve articles described the importance of both cultural, religious faith and homophily factors.

Cultural differences can be seen as a barrier to the process $[11,13,15,49,50]$ and therefore, cultural changes must take place so as to create effective partnerships and the partnership itself must take into account cultural differences and have cultural competence $[11,14,16,17,21,51]$. Additionally, common religious faith and homophily contribute to the establishment of the partnerships [26,52]. However, religion itself can act as a barrier and cause a lack of engagement on the part of partners [52].

We found the topic of political factors mentioned in five articles. Having a favorable political climate is essential to the sustainability and performance of the partnership [19,44,53]. Unwillingness on the part of governmental organizations [28] to let go of control and their inflexibility can be a major difficulty, as can be the broader political influence that these organizations can have upon the partnership itself [11].

\section{Membership (53 articles)}

Regarding the characteristics of the members that influence the development of the partnership, the relationship between the partners is key and this was commented in fifty-three articles. A history of partnerships with conflict $[14,17,22,25,54]$, conflicting regulations [13] limited collaboration [25], little or no experience of joint working $[33,53,55]$, or where partners are being ignored are detrimental to any partnership. In addition to these aspects, differing agendas between partners, lack of involvement and collaboration, and poor inter-professional partnerships appeared in eighteen articles $[10,11,13,14,38,46,49,52,55-59]$. Feelings of competitiveness or perceived competition, tension, competing priorities amongst the partners [13$15,17,23,25,39,51,53,58]$ and lack of trust/confidence $[11,13-15,19,37,44,52,60]$ appeared as barriers to the development process. Furthermore, absence of flexibility $[19,33,39,61]$ and resistance to change on the part of the leaders, team members and the organization $[12,15,22,26,52,54,58,62]$ were seen as hindrances, as was the lack of clarity and understanding about the roles $[10,15,22,33,39,47,55,58,62]$ within the partnership. As noted above, a good understanding of the roles is fundamental in a partnership.

In contrast, positive past experiences in other partnerships and with the community can influence and motivate the current partnership $[15,19,21,22,24,36,49,52,53,63]$. Establishing a climate of trust and confidence between the partners, as well as, between these and the members of the community is a challenge [10-15,19-21,24,25,27,28,37$39,43,46,48-51,53,55,62,64]$. As [46] highlights, the potential for conflict exists in all partnerships, and thus, having mutual respect $[12,14,20,21,27,36,39,46,52,56,59,60]$, engaging in conflict resolution $[17,32]$ and developing trusting, strong and positive relationships between partners, with the community and with structures of power and influence is essential $[13,19,20,32,33,36,38,42,45,48-52,56,58-60,62,63]$. Cooperation or collaboration is necessary in the partnership and is of interest to all parties, resulting in the creation of synergy and linkages amongst them [13,15,22-24,26,28,35,49,53,55,57]. Moreover, flexibility in terms of the relationships between partners and in the partnership's procedures was considered to be fundamental $[10,19,25,32,46,48,61,62]$. Notwithstanding, in any successful partnership, mutual benefits are essential and must be clearly identified. Some of the benefits include access to resources, shared risk, shared costs, shared successes/results, shared knowledge/information and skills, and increased efficiency, visibility and credibility $\quad[13,17,19,21,23,24,26-28,32,38,45,46,49,52,59]$. The partnership itself should create opportunities to involve the partners, holding them each accountable and helping them grow. Such opportunities can include the sharing of information and resources $[14,21,39,43,46,48,51,59]$.

A number of articles emphasized the sharing and integration of knowledge, competencies, and skills $[10,14,15,19,21,24-27,30,33,45,46,49,51,55,58,64]$. The importance of the development of joint and on-going training initiatives was also mentioned in five articles $[16,39,49,52,57]$, as the workforce must be well educated and stable $[16,32,33,46,61]$. This is because insufficient training and lack of knowledge, expertise, and skills were considered to be barriers to the partnerships $[10,11,15,16,18,37,40,42,47,51,57,58,60,61,64,65]$. Similarly, high workloads and being overburdened were also identified $[13,16,18,21,23,31,32,39,42,51,58]$.

Personal attitudes, behaviors, values, and preconceptions were presented in various articles as obstacles $[11,16,19,39,52,54]$, as well as, inadequate understanding $[15,17,32,49,55,56,58]$ and lack of capacity or the feeling of incapacity leading to failed partnerships $[15,34,35,49]$. As such, attitudes, behaviors, and values 
that contribute to a successful partnership must exist $[10,11,15,16,19,23,26,28,36,39,40,42,46,48,50,51,53,55$, 56,58-61]. Understanding of the needs, issues, and priorities should be mutual and shared. This understanding should keep in mind the social and political contexts as well as the challenges faced by each of the partners $[11,14,15,27,30,32-34,43,52,56,60]$. In addition to this, the awareness of the boundaries and factors that support the partnering are essential $[12,14,32,37,38,50,55,63]$, as is the ability to adapt to different situations and contexts on the part of the partners [10,19,35,36,39].

Although it was only mentioned in one article, a lack of commitment is detrimental to the partnership [15]. There were far more articles which emphasized the importance of commitment as an essential factor in a successful partnership, noting that commitment must exist amongst all partners and be long-term [21,24,31,32,45,53,56,58,62].

Article [40] noted that the recognition of the impact that the partnership had may not be immediate. On a similar note, several articles also highlighted the importance of the partners being recognized for their work, knowledge and expertise and this recognition should be shared [17,21,24,37,38,44,56,59].

\section{Process and structural (56 articles)}

Factors relating to the process of collaboration were found in a total of forty-six articles. Not having equal participation in the decision-making process and the complexity of the decisions to be made was seen as hindrances $[11,46,52,59]$. As such, shared decision-making must be inherent in the structure of the partnership and included throughout all the phases of the process. Ideally, the partners will have the same level of participation in the decision-making process [10,11,19$22,24,27,30,32,37,39,55,57,60,64]$. All partners should participate in the planning and implementation process. These processes should be effective, inclusive, innovative, and strategic in order to meet the needs identified $[10,11,15,19,21-23,25,28,31,32,35,38,39,44,64]$ and the partnership itself, should meet the needs of the partners and the organization $[23,24,46,47]$. In order for this to occur, negotiation should be present in the establishment of the rules of the partnership, in the decisionmaking, and should be mutual [14,22,27,36,49,51]. In this way, the use of flexible, innovative, participatory, multidisciplinary, and community-based methodologies in the planning, implementation and evaluation process is vital $[12,14,15,19,21,23,30,32,35-37,40,42-$ $44,47,56,58]$. Responsibilities must be clearly defined and distributed/shared amongst partners, who are held accountable [21-23,27,29,32$34,39,46,47,50,55,57,62]$. Roles within the partnership should be well-defined and shared and partners must have a good understanding of these roles
$[15,17,21,23,27,32-34,36,38,39,51,53,55,57,62]$. This implies that protocols and procedures must be well defined, common and shared in order to promote integration [21,32,36,51-53,56,57,59].

Just as developmental and/or factors relating to the process were highlighted in the literature, so too were structural elements, which were mentioned in forty articles. The absence and/or inadequate structure or differing structural or organizational characteristics amongst the partners was seen to be an impediment $[11,13,28,31,44]$. Organizational dynamics, inertia, instability $[10,13,58,61]$ and unstructured meetings, which were unproductive and few and far between $[21,46]$, were obstacles to overcome. Meetings should be frequent, planned well in advance, be effective, have clear objectives, and involve and engage all partners $\quad[10,18,21,23,25,27,31,36,38,39,46,48,51,55,56]$. Another impeding factor mentioned was the inherent dimension and capacity of the partnership to provide services $[13,41,54]$. Improving the capacity to provide care was seen as a challenge [57]. Absence and/or inadequate administrative, organizational, cultural and community/social support was evident in several articles [20,44,45,58,65]. Support should be ongoing and mutual and should come from various levels (administration, community/society leaders, funding, social, cultural and religious) $[15,17,27,28,40,45,47,50-52,57,58,62,65]$. Creating and developing effective and clear structures that sustain the partnership is essential [15,22,31,36,56,59], as well as having a capacity building as a structural factor $[16,17,19,21,26,27,36,50,59]$. Another fundamental structural factor of the partnership having a sense of advocacy as part of the 'mission' [10,26,40,60,62]. The partnership itself encouraged members to advocate on issues and gave them a stage to be heard [52].

\section{Communication (34 articles)}

Another factor that was highly discussed was communication, appearing in a total of thirty-four articles. Inadequate and ineffective communication [18,22,57] was found to hinder the partnership as well. Poor communication or the lack thereof $[18,20,42,46,52]$ was also highlighted and was seen as a problematic factor in the development of the partnership. Nonetheless, communication was also considered to be a challenge in that the quality of the communication must be honest, open and clear, effective, consistent, constructive and sustained. Furthermore, the sharing of information is also fundamental. The instruments and methods or strategies and processes through which communication is established and carried out in the partnership must also be considered $[11,14,15,17-19,21-25,27,28,30,31,35,36,38,39,48,50-$ $52,55-58,60-63]$. 


\section{Purpose (31 articles)}

Thirty-one articles identified the factors relating to objectives, vision, and mission. A lack of clear vision $[10,14,15,28,38]$ or common mission [61], limited objectives and non-sharing of these objectives between the partners was highlighted in six articles. To have a successful partnership, a common mission $[24,52,61]$ must exist and the purpose, vision, and goals of the partnership should be clear, common, concrete, and mutually agreed-upon. These objectives should be achievable [10-12,15,19,21-28,31,36,38$40,46,47,49,51,52,55,58,60,62,63]$. In turn, the partnership itself gains credibility by providing visibility of work accomplished or results [45]. Furthermore, the individual members also benefit from the partnership in that they themselves gain credibility by being part of the same [52].

\section{Resources, leadership and power (50 articles)}

Factors relating to resources were given great importance in the literature, appearing in forty-eight articles. A significant obstacle in the development of the partnerships was the limited and/or inadequate resources, namely, human capital, facilities, materials, time, money, amongst others [11-13,15-17,19,23,29,30,34,39,44-49,51$55,58,59,61,65]$. In this review of the literature, time and financial factors were found to be the most important. The lack of time and needing to work over-time appeared in sixteen articles [15,20,21,30,42$44,47,49,52,55,58,59,62,63,65]$. Lack of or limited funding cause's instability or insecurity in the partnership $[11,13,15,17,19-21,23,28,29,42,45,49,52,59,65]$ and the potential benefits of the partnership may not compensate for the costs incurred and the unanticipated costs of the partnership [33,49,54]. Another problem encountered was the non-sharing of resources by the partnering entities [19]. Additionally, having sufficient resources (staff, time, materials, etc.), the use of pre-existing resources within the community and the maximization and sharing of resources is a constant concern $[21,23,24,26,27,31,32,36,38,39,44,52]$. Having enough time to make the partnership successful $[23,49,60]$, which implies investing time in the development of the partnership and adequate, shared, and long-term funding throughout the entire program of the partnership is essential $\quad[13,15,22,28,29,32,34,38,45,49,52,56,57,61]$. Evaluating the cost-effectiveness of the partnership as well as its performance systematically, using tools and guidelines already defined/established in the planning process, is also key $[15,19,21,25,29,31,39,40,55,63]$. The very lack of assessment tools and lack of time to evaluate is a problem [32,33].

In twenty-three articles, the subject of leadership and factors relating to power were mentioned. The fact that the partners are entering into a partnership may lead to the perception that with the partnership, they, as individual partners, may experience shifts of power and lose privileges $[49,51]$. The partnership itself may result in the unequal distribution of power [28] or perception thereof [14] and sometimes, even in a lack of power on the part of some members [59]. Inadequate leadership and problematic or unstable leadership can act as barriers, as well as the existence of problems in leadership succession $[11,15,19,23,58]$. Having an effective and strong leadership that is both flexible, shared and coordinated amongst the parts, in turn, leads to a maximization of resources and reduces conflict $\quad[10,11,13-15,19,22,27,31,32,38,46,51-53,60$ 62]. Power should be equally distributed and exercised and all partners should have the power to positively influence the partnership [11,14,32,51,52].

The literature reviewed highlighted that many of these are key factors for long-term sustainability of the partnership, such as relationships, commitment, communication, funding, and structure $[15,17,19,22,35,47,54,56,57,63]$. Having a favorable political climate is essential to the sustainability and performance of the partnership $[19,44,53]$. Creating and developing effective and clear structures that sustain the partnership is essential $[15,22,31,36,56,59]$. This topic appeared in fifteen articles.

\section{Discussion}

The focus of this review was to identify barriers, obstacles, difficulties and/or challenges in the development of health partnerships in community intervention projects as identified by literature.

This was already reflected in the Ottawa Charter [5], which states that the promotion of health requires coordinated action by various sectors of the community, as well as, the encouragement of active engagement of citizens, leading to their empowerment. Health promotion works through concrete and effective community action in setting priorities, namely by developing community intervention projects, which implies making decisions, planning strategies and implementing them to achieve better health $[5,66,67]$.

However, we have found that there are still few studies published that address the subject of this review. According to the literature which we found, there are several factors that influence these process of collaboration and partnership working, which involve the community organizations/ institutions.

We grouped these factors into six categories according to Wilder Research Center have analysed. As is evident by our results, our categories corroborate the categories that Mattesich, Murray-Close e Monsey identified $[3,4,9]$. We categorized factors relating to environment; membership; process and structure; purpose; communication, and resources using the same terminology. Meanwhile, in the resources category, 
we include leadership and power. In each of these categories, we present the factors that are related to them and the ways that they can influence the development of those collaborations. Many of these factors are key to long-term sustainability in the process of partnership development. In the steps that DeLizia [68] presents to explore new leadership, sustainability (the fifth and final step) presupposes long-term thinking.

\section{Environment}

Of the fifty-six articles reviewed, forty-four dealt with factors relating to Environment. When speaking of 'environment', we are referring to the community setting in which the partnerships are particularly involved. Some authors mention that this involvement is a result of the direct influence of factors from that particular setting. This influence can occur in all of the phases of the development process [4,69-71] and can reinforce or hinder the process of collaboration $[4,72]$. The contextual factors identified in the present review corroborate those identified in previous studies.

Thus, we found contextual factors relating to connections with the communities, the sense of community within the partnership, and the vision of a community-based partnership. The involvement/ engagement and the participation of the community, as well as the legitimacy of the partnership in the eyes of the community, were also identified. In addition, we considered factors related to the geography; culture; religious faith and homophily, and politics.

The connections with the communities were described by Foster-Fishman et al. [73] as a specific category of the relational capacity, one of the four critical levels of collaborative capacity (within their members; within their relationships; within their organizational structure; and within the programs they sponsor), that partnerships need to develop $[73,74]$ to promote effective collaboration and build sustainable community change [75].

Also, the National Network for Collaboration [72], within the Collaboration Framework, presented Connectedness as one of the six contextual factors (connectedness; history of working together; political climate; policies/laws/regulations; resources; and catalysts) that have been identified as important to the success of a collaboration $[4,72]$.

At the community level, these linkages between individuals, groups, organizations, and as a whole, refer to universally understood principles and values of the community [72]. Thus, for the development of partnerships in a community context, the principles, values, and processes associated with collaboration must be deepened [4].

The sense of community has been defined and/or studied by various authors and in a variety of contexts since 1974 [76-83]. We highlighted Chavis and Wandersman [79] that postulated that a sense of community can have a catalytic effect on participation and community development [79].

According to McMillan and Chavis [78], the sense of community is a feeling that members belong, a feeling that members matter on an individual and community basis, a feeling that members' needs will be met through the partnership and that for this to occur, a shared emotional connection must be created, which entails the sharing of common experiences and history [75,78].

This sense of community was also labeled as an important dimension of community capacity in several studies $[75,81,84]$. Developing it allows for community capacity building by empowering community members to feel connected and thus, work together to achieve common community goals [85]. This a necessary condition for the community-based health promotion and disease prevention project/programs [75]. Little or no sense of community has been reported as one of the reasons as to why people do not participate in these development activities [82].

Taking a community-based approach by the partnership is crucial to create social and political change and improve health, however, the path associated with the development of partnerships in this sense is complex. This process of collaboration requires a commitment of all stakeholders to jointly achieve common goals, sharing decision-making and the allocation of resources $[9,86,87]$.

The active and democratic participation of community, its involvement and, consequently, the community empowerment, which according to WHO [88], is more than the involvement, participation or engagement of communities, implies community ownership and action that explicitly aims at social and political change [88], are essential conditions that the partnerships must take into account for the success of interventions, with view to the sustainable community development [89-92]. Without the citizens participating in any project/program, there can never be community development [89].

Participation is seen as another dimension of community capacity by several authors [4,85,90,93-97] which, along with leadership, community resources, social network, and community power, represent a community's social capital, and are imperative for achieving systematic changes in the local community $[85,95]$.

For collaborative capacity within the community, the partnership's members must hold a positive view of themselves and their role as well [73]. When they perceive their own legitimacy in the collaborative effort (e.g. [98-100] and recognize their own participation competence $[98,101,102]$, members are more likely to actively participate and contribute their knowledge and skills to the group [73,101-103]). 
In the scope of contextual factors, it is also important to comprehend how geographic factors can influence partnership work in the community. Associated with this dimension we found the distance between partners and the distance to the facility for participants from the community. Mattesich and Monsey [104] argue that partnerships developed in communities of smaller geographical areas are more likely to succeed since planning and implementation of activities are more easily managed. In these smaller contexts, faceto-face meetings are commonly used by members of the community $[4,104]$.

In our review, we found twelve articles that addressed cultural, religious faith and homophily, and political factors within partnerships. Any open discussion of faith-health partnerships must admit the complexity of this type of collaboration. Also, this may be related to the lack of cultural competence ${ }^{1}$ and possible devaluation of its influence in the establishment and development of partnerships. Some authors suggest that cultural competence is an important factor for the success (or failure) of collaborations [105,106]. This implies the need for critical awareness of these issues among professionals [105]. A systematic review demonstrated that cultural competence training shows promise as a strategy for improving the knowledge, attitudes, and skills of health professionals [107] and fundamental to eliminate the racial and ethnic health disparities [108].

To corroborate with the results of our review and as part of an evaluation of the Institute for Faith and Public Health Collaborations, representatives of 34 faithhealth teams identified that major facilitators to faithhealth collaborative work were passion and commitment, importance of faith-based organizations in communities, favorable political climate, support from community and faith leaders, diversity of teams, and mutual trust and respect. Concomitantly, they point out that unique barriers to faith and health collaboration included discomfort with faith-based organizations, distrust of either health agencies or faithbased organizations, diversity within faith communities, different agendas, separation of church and state, and the lack of a common language. Findings suggest that faith-health partnerships face unique challenges, but are capable of aligning resources to address health disparities [109].

Similarly, as mentioned above, the political climate was also considered by the National Network for Collaboration [72] as an important contextual factor to the success of a collaboration. This political climate is developed surrounding the relationship with the organizations with political mandate and decision- making processes. When this relationship is made in collaborative political climates (favorable political climate as mentioned in our review), there is a willingness to dialogue, accept and negotiate new ideas, to navigate through conflict, and to be open towards emerging trends. Collaborations which have support and endorsement of key people, groups, and organizations in power are more likely to be effective in reaching the agreed-upon outcomes. Also, widespread political support is important in developing and sustaining collaborations $[4,72]$.

The aforementioned findings are in agreement with the Wilder Research Center, whose research on partnerships, identified the following three critical success factors in the Environment category: the history of collaboration or co-operation; collaborative group seen as a legitimate leader; and, favorable political and social climate $[3,9]$.

\section{Membership}

Following our review, of the fifty-six articles reviewed, fifty-three dealt with factors related to the characteristics of members.

Membership is one of the four factors (membership; influence; integration and fulfillment of needs; and, shared emotional connection) that contribute to a sense of community, aforementioned as the theory that has become the most widely accepted understanding of how communities work. For the authors McMillan and Chavis [78], membership is a sense of belonging and/or sharing a feeling of personal connectedness and it includes five attributes (boundaries; emotional safety; a sense of belonging and identification; personal investment; and, a common symbol system) [78].

In our review, the factors related to the characteristics of the members that have an impact on the processes of collaboration and influence their success in community contexts is corroborated by other authors. These results indicate that, during the process of collaboration, there are several reasons that can generate competition and tension or even conflict; which we identified as barriers. These are inherent in collaborative processes [110] and inevitable between partners [9], and may, by their dynamic nature, be overcome $[4,110]$.

It is essential to have mutual respect $[3,9]$, engage in conflict resolution [75], develop understanding and trust [3,9,111], and develop strong/positive relationships among/between partners, with the members of the community and with structures of power and influence [75], and these that should be

\footnotetext{
${ }^{1}$ Cultural competence involves understanding and appropriately responding to the unique combination of cultural variables - including ability, age, beliefs, ethnicity, experience, gender, gender identity, linguistic background, national origin, race, religion, sexual orientation, and socioeconomic status - that the professional and client bring to interactions' [153].
} 
valued $[4,112]$. This highlights the findings, that personal attitudes, behaviors, and values that contribute to a successful partnership must exist and be promoted. In a similar way, Hudson et al. [113] value joint working as a key requirement of partnership, and add that trust and respect for its members means that they are ready for this work in an informal, structured way, including all phases of the process, from planning, intervention, joint assessments and commissioning $[113,114]$.

It has been argued that partnerships can provide significant benefits [9] to solve a particular problem. Mutual benefits are essential and must be clearly identified and advertised [4]. In the early 1960s, Clark and Wilson [115] had described three types of benefits deriving from participation. They are material (increased skills, increased financial resources, valuation of property), compensatory (more interpersonal relations, more social status, identification with a group, increased cooperation rates), and strategic benefits (better definition of personal or organizational goals aimed at improving the community, greater sense of duty, greater sense of responsibility) [115]. However, in our review, we verified that some of the benefits include sharing and integration of knowledge, competencies and skills, the access to resources, information and political influence, sharing costs, risk, and successes/results. All of which results in increased efficiency, visibility, recognition and credibility of partnership. The benefits must outweigh the costs involved, but may not be immediate $[9,116,117]$. Insufficient training and lack of knowledge, expertise, and skills were considered to be barriers to the partnerships. This highlights the importance of the development of joint and on-going training initiatives $[113,114]$.

The capacity to take on commitment or the effective participation in the processes of change are some dimensions related to community capacity [75], which are essential challenges for a successful partnership and must exist amongst all partners and be long-term. A lack of commitment is detrimental to the partnership. As an effective way of maintaining commitment, several authors mention the need for all members of the partnership to be attentive to the 6 R's [117] to remain involved and active in fulfilling the design or common purpose of the partnership [4]. Corroborating with what has been mentioned, recognition, respect, relationships, reward, and results are five of those six elements that are to be considered in this process. In terms of the relationships between partners, flexibility was considered, in our review, to be fundamental.

Regarding the sixth element, we agree that for the proper functioning of a partnership, it is relevant that the roles/responsibilities and division of labor are clearly defined and there is a good understanding and acceptance by those who assume this responsibility. The partnership should provide opportunities to actively engage partners, holding them each accountable and helping them grow together. Furthermore, understanding of the needs and issues, or the priorities and goals to address them, should be mutual and shared. The awareness of the boundaries and factors that support the partnering are essential, as is the ability to adapt to different situations and contexts on the part of the partners.

In a partnership, all these factors will surface and impact the ability of the group to effectively work together. The history of past relationships between the organizations involved or in other partnerships and with the community can influence and motivate the current partnership [9].

In this category, in brief, we present the four critical success factors identified by the Wilder Research Center, which we corroborate and which are: mutual respect, understanding, and trust; appropriate crosssection of members; members see collaboration as in their self-interest; ability to compromise $[3,4,9]$.

\section{Process and structural}

Factors relating to the process of collaboration were found in a total of forty-six articles, while factors related to structural elements were mentioned in forty articles.

As mentioned by The National Network for Collaboration [72] Process Factors focus on the 'how-to' aspect of collaboration. Each of the factors identified by them covers a broad range of skills and/or components/tasks necessary to build effective working relationships and contribute to the capacity of a community, impacting on the collaboration process [72].

In the present review and according to the literature, in the performance of their role in both the process and in the structure of the partnership, the members to feel that they have power in decision-making [3,4].

But managing the decision-making process is considered one of the main organizational challenges. Also, for creating and maintaining a sense that participation is worthwhile is to use collaborative strategies that can achieve small success quickly and reinforce the benefit of participation. For engagement to succeed the participation of members of the partnerships in all phases of the process has to be safeguarded (principle 5 of Community Engagement) and be flexible enough to meet a community's changing needs (see principle 8 of Community Engagement) and to achieve objectives established in the partnership. Partnerships require continuous and often delicate negotiation among their members in the establishment of its rules and in the decision-making, which should be mutual and shared [116].

Related to these aspects are the membership characteristics discussed above. Of note, the adaptability of members to the diversity of situations that arise in 
order to continue the work of the partnership. According to Ornelas and Vargas-Moniz [4, p. 143], the group has the ability to stay on the diverse paths of social change, even if it needs to clarify, adjust or change some of its objectives, strategies or members to deal with conditions of change [4].

However, in the partnership's work, it is necessary that the activities do not represent an overload for the partners. To this end, the challenge is to introduce changes in the process and structure that leads to a development carried out at an appropriate pace [4].

For the success of a partnership, its members are faced with the challenge of clear understanding of their roles, rights, and responsibilities. Also, there is a need for the development of policy guidelines and a clear process for making decisions among the partners in this collaboration [118]. The results of our review reinforce this challenge, stating that to promote integration, protocols and procedures must be well defined, common and shared.

Interactive participation tends to involve interdisciplinary methodologies that seek multiple perspectives and make use of systematic and structured learning processes [119-121]. In corroboration with these authors, in our review, in terms of the process of collaboration, the flexible, innovative, participatory, multidisciplinary, and community-based methodologies were considered to be fundamental.

The systems perspective draws attention to the diversity of roles that different people and organizations play in the functioning of a community. In planning, designing, and implementing approaches in the partnership to engage a community will require the use of multiple engagement strategies [116].

Since the structure is a fundamental aspect for the involvement of the partnership itself, it is important to realize if the elements that are conducive to its effectiveness are guaranteed. In this sense, it should be noted that there are regular meetings with the knowledge of all members; the existence of active working groups or commissions; knowledge of statutes, legislation or regulations by all partners; frequent communication and coordination of the action of the partners with the different stakeholders; and the existence of regular and participatory meetings by the coordinating group $[4,110]$. Several authors have concluded that the more formally a partnership is organized, the greater its likelihood of success $[4,103,122,123]$.

The results of this review confirm that best practices around structure and organizational capacity involve the creation of effective and clear structures, capacity building, clear decision-making processes, and the acquisition of the key resources and support from various levels necessary to the organization.

Another fundamental structural factor of the partnership found in this review was having sense of advocacy as part of the 'mission'. The partnership itself encouraged members to advocate on issues and gave them a stage to be heard.

In this category, we present the factors related to the process and structure identified by the Wilder Research Center, which we corroborate and are: members share a stake, multiple layers of participation, flexibility, clear roles and policy guidelines, adaptability, and appropriate pace of development $[3,4,9]$.

\section{Communication}

Another factor that was highly discussed in this review was communication, appearing in a total of thirty-four articles.

Everett Rogers [124] defined communication as a process in which participants create and share information with one another in order to reach a mutual understanding [124].

Communication is considered one of the six major process factors identified by the National Network for Collaboration [72] and covers a broad range of skills or tasks which impact the process of collaboration. In this process, collaborative efforts depend upon open and clear communication [72] and in turn, this communication is able to link stakeholders, to ensure their involvement $[9,125,126]$.

Members of the partnerships should serve as facilitators providing guidance and voiced suggestions. The sharing of information has been understood to be key to the process. However, dissimilarities in educational level and experience between the members and variations in socioeconomic status, positions, and community roles among members created underlying hierarchies within the group [116]

For the successful engagement of community partners and key contact people within the communities, in addition to trusting relationships and mutual respect, it is also extremely important to have honest, open, constructive communication [116,127]. Furthermore, effective communication between stakeholders throughout the process is crucial so that everyone understands what is required of them [128].

In much of our literature review, the role of honest, open, clear, effective, frequent, consistent, constructive and sustained communication is at least implicit and sometimes explicit, also corroborating the findings of Wildridge et al. [9].

On the negative side, the results of this review indicate that an inadequate, ineffective, and poor or lack of communication, is a barrier to the development and successful partnerships.

As Hudson et al. [113] notes, 'a contrary case of collaboration could be seen in organizations that communicate [113] with each other, but only as far as they need to in order to deliver services $[114 \ldots$. The frequent liaison may give the impression of collaboration when in fact the expectation of reciprocation may 
reveal a different state of affairs' ]. Also, it is not surprising that collaborative working between different professional groups is challenging. As members have different professional backgrounds, the language or terminology utilized may not be understood by the other members, resulting in a 'breakdown' in communication [114,129].

The members must assure 'language usage' which is acceptable and understood to all members. This means that terminology must be explained so that shared meaning can take place. As a strategy, the National Network for Collaboration [72] recommends that a formal process for communication between meetings (i.e. weekly phone calls, mailings ...) with norms and channels of communicating must be established, posing a challenge for all who are involved, similar to our results. As was also noted, communication from the collaboration to the broader community must be established and establishing and maintaining non-formal communication channels with local community leaders is also essential [72].

Communication tools should be used from the outset of the collaborative process to facilitate the interaction between the members [128]. Members should interact often and make use of established informal and formal communication channels or links, resulting in a more cohesive group with common objectives $[3,4,9]$.

In this category, we briefly presented the factors related to communication identified by the Wilder Research Center, which we corroborate and are: open and frequent; and, informal relationships and communication links $[3,4,9]$.

\section{Purpose}

Following what we have been presenting and based on the classification attributed to the factors found in our review, of the fifty-six articles reviewed, thirty-one identified the factors relating to objectives, vision, and mission.

Our results are unanimous with the literature when it is stated that in order to have a successful partnership, it is important and challenging for stakeholders to have the opportunity to come together to develop and share their visions, and agendas [128], and that a common mission must exist.

To define the direction and focus of collaboration implies that the vision, mission, values, and principles should be established initially. Having a clear direction and focus allows the members to define the purpose of the collaboration as they see fit. In doing so, an identity and fundamental objective are created. It is this commonality that brings members together to focus on achieving a mission [72], which in turn, can be a challenge for all. Diverting energy and resources away from core aims - mission drift is considered one of the potential risks of collaborative working [130].

An initial strategic vision can be developed by those stakeholders who have actively engaged in the process. As the plan for the collaboration is developing, there is recognition that the stakeholder must be actively involved in dialogue and action. The more powerful and influential members must be involved as early as possible so as to achieve the vision of the partnership. The earlier that key members are brought into the process, 'the more sound and realistic ultimate collaboration is likely to be', and seen favorably by the community [128].

This collaborative process allows groups with similar or different perspectives can exchange viewpoints and search for solutions that go beyond their own vision of what is possible. However, this collaborative process is fraught with difficulties and will go through many 'iterations' [128]. According to our results, for the collaboration or partnership to have a successful outcome, its purpose and goals have to be clear, common, concrete, achievable, and mutually agreedupon.

The articulation of common interests in the collaborative process according to this set - vision, mission, values, and principles, allows one to perceive the purpose of this collaboration at a broader level and its significance [72].

A lack of clear vision or common mission, limited objectives and non-sharing of these objectives between the partners was highlighted in six articles in our review. For instance, in a study by Wilson and Charlton [125], more than half of the participants mentioned some variation on a 'common vision' amongst their main critical success factors of partnership work [125]. Achieving a shared vision is something regularly cited as essential to a successful partnership [9,131135]. The shared vision may exist at the outset of collaboration or the partners may develop a vision as they work together [118].

In the process of developing the partnership, it is usually possible to acquire a deeper knowledge of each of the entities involved, a greater visibility not only of their purposes, but also about their capacity for work accomplished and social and political influence [4], gaining credibility in the larger environment, according to the results of our review. Furthermore, the individual members also benefit from the partnership in that they themselves gain credibility by being part of the same.

To achieve the partnership goals and complement the intended purpose of the partnership are required management practices and resources. Therefore, members must demonstrate accountability for intervention and domain of delivery of the objectives and targets for which they are responsible [136]. Also, advocacy, linked to accountability, will focus on mobilizing 
sufficient and sustainable resources and effective use of these resources [138], contributing to the success of the partnership.

In this category, we present in summary form the factors related to the purpose and which can positively or negatively influence the success of collaboration: concrete, attainable goals and objectives; shared vision; and, unique purpose $[3,4,9]$, which are in tune with results we obtained.

\section{Resources, leadership and power}

Of the fifty-six articles reviewed, forty-eight articles identified the factors relating to resources and in twenty-three articles, the relationship between leadership and factors relating to power were mentioned. We then discuss, in conjunction with the conclusions of other studies, the possible reasons why these factors can be considered barriers, obstacles or challenges to the success of the partnerships.

The National Network for Collaboration [72], within the Collaboration Framework, presented Resources as another of the six contextual factors that we have already mentioned and that they were identified as important to the success of a partnership [4,72].

When defining partnership as an organization of diverse interest groups that combine their human and material resources to effect a specific change the members are unable to bring about independently, Brown $[137$, p. 4] is reinforcing the importance of the coalition-building [137] as inter-organizational, cooperative and synergistic working alliances [69].

Our results have allowed us to verify that there is a constant concern for pre-existing resources to be maximized and shared, even if being considered sufficient. However, the existence of partner entities that do not share their resources was considered an obstacle or barrier to collaboration [109].

In the process of developing a partnership, the sharing of resources may be usually at stake, according to Whitt [139], which contributes to greater accessibility to other logistical services (facilities, equipment, communications), greater visibility (greater access to the media and / or the media interest in their actions) and greater knowledge (access to networks of professionals or experts in thematic areas of interest to the partnership) $[4,139]$.

The resources of a community are made up of all the human and material 'input' made available to the partnership [4] and are necessary to develop and sustain them [118]. Elements of a geographical or even climatic nature may be included and become decisive, as they determine the possible places or times for scheduling meetings or for organizing/implementing actions related to the partnerships $[4,140]$.
The National Network for Collaboration [72] specifies that, within a collaboration, resources refer to four types of capital: environmental, in-kind, financial, and human.

An environment where there is connectedness at all levels increases the probability of a successful collaboration. From the outset of the partnership [128], its members should be familiar with what each contributes to the partnership (in-kind), such as meeting rooms, supplies, and computers... [72], to get a sense of the necessary and existing resources.

Many of the barriers to collaboration identified in this review were similar to those identified in other collaborative works including limited resources, either financial resources, human resources, or both. We found that almost half of the articles considered that limited and/or inadequate resources are an obstacle to the development of the partnership. Kegler et al. [109] highlight that a large number of participants discussed the lack of funding, in particular, related to budget cuts affecting current programs [109]. Also, the lack of or limited funding cause's instability or insecurity in the partnership. This reinforces what has been described, that some stakeholder conflicts are based on a shortage of resources (natural, financial, institutional, and professional) [128]. Thus, we confirm that having adequate, shared, and long-term funding throughout the entire program of the partnership is essential and that financial factors are among the most important.

However, other authors report that collaborations that cooperate only to seek funding are more likely to fail than collaborations that form as comprehensive community-wide responses to a problem. In addition to the financial capital, there is also no doubt that human capital is an also important asset in collaboration and constitutes a crucial investment for sustainability. But the contribution of each collaboration member and organization can be in one or all four of the types of capital mentioned previously [72].

Corroborating our results, and still related to human capital, to achieve a collaboration's shared vision, its members have to invest time, expertise and energy [72]. In a study by Kegler et al. [109] the lack of time to do collaborative work was the most frequently cited barrier, sometimes because of conflicts between collaborative work and other obligations. Also, in the same study, a large number of participants discussed limited staff time for new initiatives and increased competition between organizations [109].

Time management is an important organization/ participant factor, particularly for partnership building and maintenance [141]. If, on the one hand, the burden of extra time required has been the reason why some members withdraw from the partnerships [15], on the other, partnership members need to see and experience 'real' benefits for the extra time, effort, and involvement they are asked to give [116]. 
Partnerships involve a long-term investment in time and resources [4], so the potential benefits of a partnership may not compensate for the costs incurred and the unanticipated costs of the partnership, as found in our review. Outcomes do not justify the time and resources invested is one of the potential risks in collaborative working [130].

That is why stakeholders of a partnership should discuss whether they have the time to achieve their goals and to stimulate the collaborative process [4].

Our results demonstrate that evaluating the costeffectiveness of the partnership as well as its performance systematically, with access tools and guidelines already defined/established, is key. The literature shows an increasing interest in the evaluation of the partnership work by the fact that its members seek visibility of their collaborative action or actions that are relevant to a community $[4,143]$. However, we find that the resources available to evaluate processes and work results of partnership, in order to perceive their effectiveness or efficiency, are relatively scarce. We stress that the very lack of assessment tools and lack of time to evaluate is a problem.

According to McQuaid [142], in most partnerships, there is unequal power [142]. While this may be true, our review revealed that the lack of power on the part of some members or even the perception thereof can act as a barrier. In addition to this, members can experience shifts of power and/or lose privileges they previously had.

What is intended with any partnership, or the 'meaning' of the term partnership, presupposes a more involved form of participation and this implies power being shared equally among all partners [145]. Bennett and McCoshan [144], however, argue that the partnerships between members may be unequal as it may be more important for one partner than the other(s) and this can lead to one partner becoming more influential and powerful [144]. As previously mentioned, what is essential is that members should try to share and exercise power equally and all partners should have the power to positively influence the partnership.

While leadership is often defined as who is in power, the definition of leadership for successful collaborations is broadened to include impacts for change within their community, group and/or organization [72]. Partnerships imply shared leadership among respected individuals who are recognized and empowered by their own organizations and trusted by partners to build consensus and resolve conflicts [136]. Corroborating this idea, our results highlighted that having strong leadership that is recognized by all the stakeholders maximizes the effectiveness and results of the partnership and facilitates and supports team building. Leadership in and of itself can be 'perfected' throughout the development of the partnership [146]. As found in our review, however, it can also act as a barrier. The lack of leadership and or leadership that is unstable or problematic can be a hindrance.

In a partnership it is necessary that there is someone who takes the lead and who has the confidence and the credibility to make it move [4]. One of the major responsibilities of leadership is to assure that appropriate members have been brought to the collaboration [72], and groom people internally for succession $[72,147]$. Leaders need to think long-term and plan for the succession process, creating a link between the previous, current, and future leaders within the partnership, which in turn creates sustainability [4,73]. As Cascio [147] stated: 'leadership succession is too important to ignore' [147].

In this category, we present in summary form the factors related to resources, which can positively or negatively influence the success of partnership [3,4,9] and that are in tune with the results obtained by us. For Mattesich and Monsey [118], resources include financial and human 'input' necessary to develop and sustain a partnership [118]. In the financial field it entails having sufficient funds, and staff, materials and time. The members of the partnership have an adequate, consistent financial base to support their actions. While in human 'input' there is a skilled convener or skilled leadership. The individual who convenes the members of the partnership has organizing and interpersonal skills and carries out the role with fairness. Because of these characteristics (and others), the convener is granted respect or 'legitimacy' from the partners $[3,4,9]$. In the matter of skills to lead a community partnership process, Melo e Alves [120] identify the partnership process as a clinical decisionmaking process integrated in Community Health Nurses Diagnose and intervention with communities [120], witch demands more studies about intentional integration of partnerships in public and community health leaders.

Further to our discussion, sustainability has been identified as an important process factor of a partnership. It also covers a broad range of skills or tasks which impact this process and is often dependent on policies and practices in place [72]. Having a favorable political climate is essential to the sustainability and performance of the partnership, as already mentioned above in Environment. Thus, when there is an environment with connections at all levels, a history of working together, a political climate of support, and policies, laws, and regulations that encourage cooperativeness there is a likelihood of increasing successful collaboration [72].

For the maintenance and sustainability of a partnership, it is important to know, through joint reflection, the current level of collaboration between members and whether collaborative efforts maximize the effectiveness of the partner organization [4]. Various 
authors state that the sustainability of a community partnership is anchored in continued training and technical assistance to build upon the partnership's capacity and influence $[4,69,143,148,150]$.

Community collaboration requires a long-term commitment by the engaging organization and its partners, giving them, therefore, a greater capacity for making a difference in the health of the population. However, the development of successful joint community action takes time. The probability of sustained engagement, and meaningful and effective programming increases when community participants are active partners in the process and are ready for collaboration and leadership [116]. Shediac-Rizkallah and Bone [149] bring us the idea of Community Ownership that associates citizens' sense of community destinations with sustainability-oriented planning processes $[4,149]$.

Two coalition case studies follow the discussion of dimensions related to coalition success and illustrate the highly complex practice of building successful community coalitions. These dimensions are related to coalition readiness, intentionality, structure, and organizational capacity, taking action, membership, leadership, money and resources, relationships, and technical assistance. That once exploited, best practices are delineated [152]. Also, in a large postal survey of attitudes to intersectoral working, Jones and Barry [151] found that the most important predictors of sustainable partnerships were the trust and leadership [151].

In addition, to a sustained and collaborative membership, resources and strategic program planning must also exist. Planning must be both short-term and long-term. The collaboration must be able to identify emerging trends and issues and develop strategies for needed expansion [72]. As noted in principle 7 of Community Engagement, sustainability results from identifying and mobilizing community assets and from developing capacities and resources [116]. Financial resources are necessary for the maintenance and sustainability of the partnership's activities and its functioning [4].

\section{Implications for healthcare management}

In order to positively change the way organizations have come to work/function in the process of collaboration, the factors identified in this review must be taken into consideration. As such, in the development process of a community partnership, it is recommended that the partners involved discuss and seek to tackle each of these factors, which will allow for a greater possible consensus.

The partners should have knowledge of the factors relating to the community/society, pre-existing resources, and cultural/religious, geographical, and political characteristics. They should also keep in mind that the personal attitudes and personal and/or professional characteristics of the members, which can influence the development of the partnership in a negative or positive way. The structure and organization of the partnership, as well as all of the phases of the process, which implies the planning, implementation and the evaluation of said partnership, must be considered. The use of communication methodologies will promote the involvement of all of the partners/ community in the decision-making process and thus the importance of communication procedures amongst the partners and the community, as well as having strong leadership. The responsibilities/roles of the members must be well defined. Also vital is the existence of clear and shared objectives, values, a sense of a common mission and financial resources and time. The partners must consider all of these factors and must understand how the partnership will be sustainable in the long term. The evaluation terms of the impact of the partnership should be established at the beginning of the development of the process.

\section{Disclosure statement}

No potential conflict of interest was reported by the author(s).

\section{Notes on contributors}

Odete Maria Azevedo Alves is researcher of Universidad do Porto and a lecturer in public and community health. Her research interests include the development of health partnerships in community intervention projects. Odete is expert in Nursing and over 25 years work experience in different areas of healthcare.

Joaquim Paulo Moreira is professor of health policy and management and in the past fifteen years has held several international and national executive positions in the field of health management and communication. His research interests include the development of integrated health care. Collaboration in this article took place in the support and supervision of the $\mathrm{PhD}$ project of the main author.

Paula Clara Santos is professor of Physiotherapy at School health of polytechnic Institute of Porto and researcher at CIAFEL e CIR. She works in the areas of physiotherapy in the community; health promotion and women's health. In the last thirty years has held work experience in community projects in partnership with various national and international institutions. Her research interests include projects of health promotion. Collaboration in this article took place as an independent reviewer, and in support of analysing results.

\section{ORCID}

Odete Maria Azevedo Alves (D) http://orcid.org/0000-00021294-3407

Joaquim Paulo Moreira (D) http://orcid.org/0000-0002-36441022

Paula Clara Santos (D) http://orcid.org/0000-0003-3548700X 


\section{References}

[1] WHO Regional Office for Europe. Towards environmentally sustainable health systems in Europe. A review of the evidence. Copenhagen: WHO; 2016.

[2] WHO Europe. Health literacy: the solid facts. Geneva: World Health Organization; 2013.

[3] Mattesich PW, Murray-Close M, Monsey BR. Collaboration: what makes it work, 2nd edition: a review of research literature on factors influencing successful collaboration. 2nd ed. St. Paul (Minn): Turner Publishing Company; 2001, Jan 6.

[4] Ornelas J, Vargas-Moniz M. Parcerias comunitárias (community coalitions). 1st ed. Lisboa: ISPA - IU Coleção Livros Técnicos; 2011.

[5] WHO. Ottawa Charter for Health Promotion; 1986.

[6] National Library of Medicine. Medical subject headings. Maryland: U.S. Department of Health \& Human Services; 2016. Available from: https://www. nlm.nih.gov/mesh/meshhome.html.

[7] Tricco AC, Lillie E, Zarin W, et al. PRISMA extension for scoping reviews (PRISMA-ScR): checklist and explanation. Ann Intern Med. 2018;169(7):467-473.

[8] Williams C. Research methods. J Bus Econ Res. 2007;5(3):65-72.

[9] Wildridge V, Childs S, Cawthra L, et al. How to create successful partnerships-a review of the literature. Health Info Libr J. 2004;21(Suppl 1):3-19.

[10] Tataw D, Bazargan-Hejazi S, James FW. Actualizing a provider alliance to expand health services access to a low-income urban community. Soc Work Public Health. 2011;26(7):651-671.

[11] Taylor-Robinson DC, Lloyd-Williams F, Orton L, et al. Barriers to partnership working in public health: a qualitative study. PLoS One. 2012;7(1):e29536.

[12] Battaglia TA, Murrell SS, Bhosrekar SG, et al. Connecting Boston's public housing developments to community health centers: who's ready for change? Prog Community Health Partnersh. 2012;6(3):239-248.

[13] Samuels ME, Xirasagar S, Elder KT, et al. Enhancing the care continuum in rural areas: survey of community health center-rural hospital collaborations. J Rural Health. 2008;24(1):24-31.

[14] Carr SM, Clarke CL, Molyneux J, et al. Facilitating participation: a health action zone experience. Prim Health Care Res Dev. 2006;7(2):147-156.

[15] Liau CY, Lin CC, Lin YK, et al. Partnership disengagement from primary community care networks (PCCNs): a qualitative study for a national demonstration project. BMC Health Serv Res. 2010;10:87.

[16] Bhattacharyya OK, Estey EA, Rasooly IR, et al. Providers' perceptions of barriers to the management of type 2 diabetes in remote aboriginal settings. Int J Circumpolar Health. 2011;70(5):552-563.

[17] Collins PA, Resendes SJ, Dunn JR. The untold story: examining Ontario's community health centres' initiatives to address upstream determinants of health. Healthc Policy. 2014;10(1):14-29.

[18] Chapin RK, Chandran D, Sergeant JF, et al. Hospital to community transitions for adults: discharge planners and community service providers' perspectives. Soc Work Health Care. 2014;53(4):311-329.

[19] Tataw DB, Rosa-Lugo Jr B. Municipal health policy development, planning and implementation: addressing youth risk factors through participatory governance. J Health Hum Serv Adm. 2011;33(4):491-533.
[20] Murphy NA, Carbone PS. Council on Children With D, American Academy of P. Parent-provider-community partnerships: optimizing outcomes for children with disabilities. Pediatrics. 2011;128(4):795802.

[21] Ma GX, Gao W, Tan Y, et al. A community-based participatory approach to a hepatitis B intervention for Korean Americans. Prog Community Health Partnersh. 2012;6(1):7-16.

[22] Merrill ML, Taylor NL, Martin AJ, et al. A mixedmethod exploration of functioning in safe schools/ healthy students partnerships. Eval Program Plann. 2012;35(2):280-286.

[23] Nation M, Collins L, Nixon C, et al. A communitybased participatory approach to youth development and school climate change: the alignment enhanced services project. Prog Community Health Partnersh. 2010;4(3):197-205.

[24] Bradshaw CP, Pas ET, Bloom J, et al. A state-wide partnership to promote safe and supportive schools: the PBIS Maryland initiative. Adm Policy Ment Health. 2012;39(4):225-237.

[25] Leurs MT, Mur-Veeman IM, van der Sar R, et al. Diagnosis of sustainable collaboration in health promotion - a case study. BMC Public Health. 2008;8:382.

[26] Ayton D, Carey G, Joss N, et al. Exploring the partnership networks of churches and church-affiliated organisations in health promotion. Aust J Prim Health. 2012;18(2):148-157.

[27] Ng C, Fraser J, Goding M, et al. Editorial Group of the Asia-Pacific Community Mental Health Development Project S. Partnerships for community mental health in the Asia-pacific: principles and best-practice models across different sectors. Australas Psychiatry. 2013;21(1):38-45.

[28] Lewis JM, Baeza JI, Alexander D. Partnerships in primary care in Australia: network structure, dynamics and sustainability. Soc Sci Med. 2008;67(2):280-291.

[29] Lhamsuren K, Choijiljav T, Budbazar E, et al. Taking action on the social determinants of health: improving health access for the urban poor in Mongolia. Int J Equity Health. 2012;11:15.

[30] De Civita M, Dasgupta K. Using diffusion of innovations theory to guide diabetes management program development: an illustrative example. J Public Health (Oxf). 2007;29(3):263-268.

[31] Jackson C, Blundell S, McEachan RRC, et al. Facilitating partnership working in public health: evaluation of a clinical service development approach. Prim Health Care Res Dev. 2009;10(3):177-188.

[32] Willcox J, Gill M. Integrated disease management programs: reflections and learnings from implementation. Aust J Prim Health. 2007;13(2):113-120.

[33] Jefford M, Kinnane N, Howell P, et al. Implementing novel models of posttreatment care for cancer survivors: enablers, challenges and recommendations. Asia Pac J Clin Oncol. 2015;11(4):319-327.

[34] Brandt HM, Young VM, Campbell DA, et al. Federally qualified health centers' capacity and readiness for research collaborations: implications for clinical-academic-community partnerships. Clin Transl Sci. 2015;8(4):391-393.

[35] Dykens A, Hedrick C, Ndiaye Y, et al. Peace corps partnered health services implementation research in global health: opportunity for impact. Glob Adv Health Med. 2014;3(5):8-15. 
[36] Naik AD, Lawrence B, Kiefer L, et al. Building a primary care/research partnership: lessons learned from a telehealth intervention for diabetes and depression. Fam Pract. 2014;32(2):216-223.

[37] Lincoln AK, Borg R, Delman J. Developing a community-based participatory research model to engage transition age youth using mental health service in research. Fam Community Health. 2015;38(1):87-97.

[38] Straub DM, Deeds BG, Willard N, et al. Partnership selection and formation: a case study of developing adolescent health community-researcher partnerships in fifteen U.S. communities. J Adolesc Health. 2007;40(6):489-498.

[39] Cronholm PF, Shea JA, Werner RM, et al. The patient centered medical home: mental models and practice culture driving the transformation process. J Gen Intern Med. 2013;28(9):1195-1201.

[40] Dobson NG, Gilroy AR. From partnership to policy: the evolution of active living by design in Portland, Oregon. Am J Prev Med. 2009;37(6 Suppl 2):S436S444.

[41] Hardt NS, Muhamed S, Das R, et al. Neighborhoodlevel hot spot maps to inform delivery of primary care and allocation of social resources. Perm J. 2013;17(1):4-9.

[42] Ross LE, Vigod S, Wishart J, et al. Barriers and facilitators to primary care for people with mental health and/or substance use issues: a qualitative study. BMC Fam Pract. 2015;16(1):135.

[43] Pearce KA, Jarrett TD, Scutchfield FD, et al. Research partnerships with healthcare providers in rural community health centers: needs and challenges in diabetes research. Public Health Front. 2015;4(1):1-6.

[44] Edwards MB, Theriault DS, Shores KA, et al. Promoting youth physical activity in rural southern communities: practitioner perceptions of environmental opportunities and barriers. J Rural Health. 2014;30(4):379-387.

[45] Reddy P, Hernan AL, Vanderwood KK, et al. Implementation of diabetes prevention programs in rural areas: Montana and south-eastern Australia compared. Aust J Rural Health. 2011;19(3):125-134.

[46] Dennis S, Hetherington SA, Borodzicz JA, et al. Challenges to establishing successful partnerships in community health promotion programs: local experiences from the national implementation of healthy eating activity and lifestyle (HEAL) program. Health Promot J Austr. 2015;26(1):45-51.

[47] Derrett S, Gunter KE, Nocon RS, et al. How 3 rural safety net clinics integrate care for patients: a qualitative case study. Med Care. 2014;52(11 Suppl. 4): S39-S47.

[48] Wong ST, Wu L, Boswell B, et al. Strategies for moving towards equity in recruitment of rural and aboriginal research participants. Rural Remote Health. 2013;13(2):2453.

[49] Lester H, Birchwood M, Tait L, et al. Barriers and facilitators to partnership working between early intervention services and the voluntary and community sector. Health Soc Care Community. 2008;16 (5):493-500.

[50] Meade CD, Wells KJ, Arevalo M, et al. Lay navigator model for impacting cancer health disparities. J Cancer Educ. 2014;29(3):449-457.

[51] Nadeau L, Jaimes A, Rousseau C, et al. Partnership at the forefront of change: documenting the transformation of child and youth mental health services in quebec. J Can Acad Child Adolesc Psychiatry. 2012;21(2):91-97.

[52] Grills NJ, Robinson P, Phillip M. Networking between community health programs: a case study outlining the effectiveness, barriers and enablers. BMC Health Serv Res. 2012;12:206.

[53] Freeman T, Peck E. Evaluating partnerships: a case study of integrated specialist mental health services. Health Soc Care Community. 2006;14(5):408-417.

[54] Scharf DM, Eberhart NK, Schmidt N, et al. Integrating primary care into community behavioral health settings: programs and early implementation experiences. Psychiatr Serv. 2013;64(7):660-665.

[55] Iddins BW, Frank JS, Kannar P, et al. Evaluation of team-based care in an urban free clinic setting. Nurs Adm Q. 2015;39(3):254-262.

[56] Boyer K, Orpin P, Walker J. Partner or perish: experiences from the field about collaborations for reform. Aust J Prim Health. 2010;16(1):104-107.

[57] Judge KS, Bass DM, Snow AL, et al. Partners in dementia care: a care coordination intervention for individuals with dementia and their family caregivers. Gerontologist. 2011;51(2):261-272.

[58] Winters L, Gordon U, Atherton J, et al. Developing public health nursing: barriers perceived by community nurses. Public Health. 2007;121(8):623633.

[59] Ruano AL. The role of social participation in municipal-level health systems: the case of Palencia, Guatemala. Glob Health Action. 2013;6:20786.

[60] Fereday J, Oster C, Darbyshire P. Partnership in practice: what parents of a disabled child want from a generic health professional in Australia. Health Soc Care Community. 2010;18(6):624-632.

[61] Morris CG, Chen FM. Training residents in community health centers: facilitators and barriers. Ann Fam Med. 2009;7(6):488-494.

[62] Lindsay S, Hoffman A. A complex transition: lessons learned as three young adults with complex care needs transition from an inpatient paediatric hospital to adult community residences. Child Care Health Dev. 2014;41(3):397-407.

[63] Porterfield DS, Hinnant L, Stevens DM, et al. The diabetes primary prevention initiative interventions focus area: a case study and recommendations. Am J Prev Med. 2010;39(3):235-242.

[64] Levesque L, Ducharme F, Caron C, et al. A partnership approach to service needs assessment with family caregivers of an aging relative living at home: a qualitative analysis of the experiences of caregivers and practitioners. Int J Nurs Stud. 2010;47(7):876-887.

[65] Trinh L, Wilson R, Williams HM, et al. Physicians promoting physical activity using pedometers and community partnerships: a real world trial. $\mathrm{Br} J$ Sports Med. 2012;46(4):284-290.

[66] Laverack G, Keshavarz Mohammadi N. What remains for the future: strengthening community actions to become an integral part of health promotion practice. Health Promot Int. 2011;26(Suppl. 2):ii258-iii62.

[67] Laverack G. Where are the champions of global health promotion? Glob Health Promot. 2012;19 (2):63-65.

[68] DeLizia J. A bumper crop. Component relations. Washington (DC): American Society of Association Executives; 2002. 
[69] Butterfoss FD, Goodman RM, Wandersman A. Community coalitions for prevention and health promotion. Health Educ Res. 1993;8(3):315-330.

[70] McLeroy KR, Kegler M, Steckler A, et al. Community coalitions for health promotion: summary and further reflections. Health Educ Res. 1994;9(1):1-11.

[71] Lasker RD, Weiss ES, Miller R. Partnership synergy: a practical framework for studying and strengthening the collaborative advantage. Milbank Q. 2001;79 (2):179-205. III-IV.

[72] National Network for Collaboration. Collaboration framework, addressing community capacity Fargo, ND: National Network for Collaboration; 1996 [cited 2018]. Available from: https://www.uvm.edu/ crs/nnco/collab/framework.html.

[73] Foster-Fishman PG, Berkowitz SL, Lounsbury DW, et al. Building collaborative capacity in community coalitions: a review and integrative framework. Am J Community Psychol. 2001;29(2):241-261.

[74] Vargas-Moniz M, Morgado J. Parcerias e coligações comunitárias: Potencialidades e desafios na criação de respostas articuladas. Análise Psicológica. 2010; 28(3):395-409.

[75] Goodman RM, Speers MA, McLeroy K, et al. Identifying and defining the dimensions of community capacity to provide a basis for measurement. Health Educ Behav. 1998;25(3):258-278.

[76] Sarason SB. The psychological sense of community: perspectives for community psychology. San Francisco: Jossey-Bass; 1974.

[77] Doolittle RJ, MacDonald D. Communication and a sense of community in a metropolitan neighborhood: a factor analytic examination. Commun Q. 1978;26:2-7.

[78] McMillan D, Chavis D. Sense of community: a definition and theory. J Community Psychol. 1986; 14:6-23.

[79] Chavis DM, Wandersman A. Sense of community in the urban environment: a catalyst for participation and community development. Am J Community Psychol. 1990;18(1):55-81.

[80] Chavis DM, Pretty GMH. Sense of community: advances in measurement and application. J Community Psychol. 1999;6:635-642.

[81] Bopp M, GermAnn K, Bopp J, et al. Assessing community capacity for change; 2000.

[82] DeNeui DL. An investigation of first-year college students' psychological sense of community on campus. Coll Stud J. 2003;37:224-234.

[83] Talò C, Mannarini T, Rochira A. Sense of community and community participation: a meta-analytic review. Soc Indic Res. 2014;117(1):1-28.

[84] Maclellan-Wright MF, Anderson D, Barber S, et al. The development of measures of community capacity for community-based funding programs in Canada. Health Promot Int. 2007;22(4):299-306.

[85] Aref F, Ma'rof R, Sarjit SG. Community capacity building: a review of its implication in tourism development. J Am Sci. 2010;6(1):172-180.

[86] Estacio EV, Oliver M, Downing B, et al. Effective partnership in community-based health promotion: lessons from the health literacy partnership. Int J Environ Res Public Health. 2017;14:12.

[87] Chandler Center for Community Leadership. Community based collaboration: community wellness multiplied; n.d. [cited 2018 April 10]. Available from: https://www.uvm.edu/crs/nnco/collab/ wellness.html\#why.
[88] WHO. Health promotion. Track 1: community empowerment. 7th global conference on health promotion: track themes. World Health Organization; 2018. Available from: https://www.who.int/ healthpromotion/conferences/7gchp/track1/en/.

[89] Onyenemezu CE. The imperative of citizen's participation in community development. Acad Res Int. 2014;5(1):209-215.

[90] Laverack G. Promoção de saúde: poder e empoderamento. Lisboa: Lusodidacta; 2008.

[91] Laverack G, Wallerstein N. Measuring community empowerment: a fresh look at organizational domains. Health Promot Int. 2001;16(2):179-185.

[92] Paul S. Community participation in urban renewal and rehabilitation: comments on theory and practices. Community Dev J. 1987;16 (7):105-117.

[93] Kegler MC, Steckler A, Malek SH, et al. A multiple case study of implementation in 10 local project ASSIST coalitions in north carolina. Health Educ Res. 1998;13(2):225-238.

[94] Chavis DM. The paradoxes and promise of community coalitions. Am J Community Psychol. 2001;29 (2):309-320. discussion 21-29.

[95] Thompson TL, Dorsey A, Parrott R, et al. The routledge handbook of health communication. New York: Taylor \& Francis; 2003.

[96] Goodman RM. Principles and tools for evaluating community-based prevention and health promotion programs. J Pub Health Manage Prac. 1998;4(2): 161-178.

[97] Laverack G. Public health: power, empowerment and professional practice. 3rd ed. New York: Palgrave; 2015.

[98] Herman KA, Wolfson M, Forster JL. The evolution, operation and future of Minnesota SAFPLAN: a coalition for family planning. Health Educ Res. 1993;8(3):331-344.

[99] McCann JE, Gray B. Power and collaboration in human service domains. Int J Sociol Social Policy. 1986;6(3):58-67.

[100] Zapka JG, Marrocco GR, Lewis B, et al. Inter-organizational responses to AIDS: a case study of the Worcester AIDS consortium. Health Educ Res. 1992;7(1):31-46.

[101] McMillan B, Florin P, Stevenson J, et al. Empowerment praxis in community coalitions. Am J Community Psychol. 1995;23(5):699-727.

[102] O’Donnell J, Ferreira, J, Hurtado, R., et al. Partners for change: community residents and agencies. J Sociol Soc Welf. 1998;XXV(1):133-151.

[103] Kegler MC S, McLeroy A, \& Malek K, et al. Factors that contribute to effective community health promotion coalitions: a study of 10 project ASSIST coalitions in North Carolina. Health Edu Behav. 1998;25(3):338-353.

[104] Mattesich PW, Monsey BR, Roy C. Community building: what makes it work: a review of factors influencing successful community building. St. Paul (Minn): Amherst H. Wilder Foundation; 1997.

[105] Browne AJ. Clinical encounters between nurses and first nations women in a Western Canadian hospital. Soc Sci Med. 2007;64(10):2165-2176.

[106] Towle A, Godolphin W, Alexander T. Doctor-patient communications in the aboriginal community: towards the development of educational programs. Patient Educ Couns. 2006;62(3):340-346. 
[107] Beach MC, Price EG, Gary TL, et al. Cultural competence: a systematic review of health care provider educational interventions. Med Care. 2005;43(4):356-373.

[108] Delphin-Rittmon ME, Andres-Hyman R, Flanagan $\mathrm{EH}$, et al. Seven essential strategies for promoting and sustaining systemic cultural competence. Psychiatr Q. 2013;84(1):53-64.

[109] Kegler MC, Hall SM, Kiser M. Facilitators, challenges, and collaborative activities in faith and health partnerships to address health disparities. Health Educ Behav. 2010;37(5):665-679.

[110] Rosenthal B. 1+1=3: a collaboration guidebook. 2nd ed Atlanta: American Cancer Society. National Advisory Group on Collaboration with Organizations; 2000.

[111] Fukuyama F. Trust: the social virtues and the creation of prosperity. New York: Free Press; 1995.

[112] Deutsch M. The resolution of conflict. New Haven (CT): Yale University Press; 1973.

[113] Hudson B, Exworthy M, Peckham S. The integration of localised and collaborative purchasing: a review of the literature and framework for analysis. UK: Nuffield Institute for Health, University of Leeds / Institute for Health Policy Studies, University of Southampton; 1998.

[114] Carnwell R, Buchanan J. Effective practice in health, social care and criminal justice: a partnership approach. Maidenhead, UK: Open University Press; 2009.

[115] Clark PB, Wilson JQ. Incentive system: a theory of organization. Adm Sci Q. 1961;6:129-166.

[116] Clinical and Translational Science Awards Consortium. Community Engagement Key Function Committee. Task Force on the Principles of Community Engagement, United States. Agency for Toxic Substances and Disease Registry, Centers for Disease Control and Prevention (U.S.). Principles of community engagement. Washington (DC): Department of Health \& Human Services, National Institutes of Health, Centers for Disease Control and Prevention, Agency for Toxic Substances and Disease Registry, Clinical and Translational Science Awards; 2011. Available from: https://purl.fdlp.gov/ GPO/gpo15486.

[117] Kaye G, Wolf T. From the ground up: a workbook on coalition building and community development. 4th ed. Amherst (Mass): AHEC/Community Partners; 2002.

[118] Mattesich PW, Monsey BR. Collaboration: what makes it work. A review of research literature on factors influencing successful collaboration. St. Paul (MN): Amherst H. Wilder Foundation; 1992; 57 p.

[119] Pretty JN. Participatory learning for sustainable agriculture. World Dev. 1995;23(8):1247-1263.

[120] Melo P, Alves O. Community empowerment and community partnerships in nursing decision-making. Healthcare (Basel). 2019;7(2):76). doi:10.3390/ healthcare7020076.

[121] Aref F. Sense of community and participation for tourism development. Life Sci J. 2011;8(1):20-25.

[122] Gotlieb NH, Brink SG, Gingis PL. Correlates of coalition effectiveness: the smoke free class of 2000 program. Health Educ Res. 1993;8(3):375-384.

[123] Kumpfer KL, Turner C, Hopkins R, et al. Leadership and team effectiveness in community coalitions for the prevention of alcohol and other drug abuse. Health Educ Res. 1993;8(3):359-374.
[124] Rogers EM. Diffusion of innovations. 4th ed. New York: Free Press; 1995.

[125] Wilson A, Charlton K. Making partnerships work: a practical guide for the public, private, voluntary and community sectors. York: Joseph Rowntree Foundation, York Publishing Services; 1997.

[126] Audit Commission. Developing productive partnerships: a bulletin; 2002.

[127] Ramsden VR, McKay S, Crowe J. The pursuit of excellence: engaging the community in participatory health research. Glob Health Promot. 2010;17 (4):32-42.

[128] World Wildlife Fund. Stakeholder collaboration: building bridges for conservation. Washington (DC): Ecoregional Conservation Strategies Unit. Research and Development; 2000. https:// d2ouvy59p0dg6k.cloudfront.net/downloads/ collaboration.pdf.

[129] Hamilton A, Wolpert D, Frith U. Your own action influences how you perceive another person's action. Curr Biol. 2004;14(6):493-498.

[130] NCVO. Benefits and risks of collaborative working 8 All Saints Street, London N1 9RL: Society Building; 2017. Available from: https://knowhownonprofit. org/organisation/collaboration/what_is_ collaboration/benefits_and_risks_of_collaboration.

[131] Hardy B, Hudson B, Waddington E. What makes a good partnership?: a partnership assessment tool. Leeds: Nuffield Institute for Health; 2000.

[132] Gray B. Collaborating: finding common ground for multiparty problems. San Francisco: Josey Bass; 1989.

[133] Knight T, Smith J, Cropper S. Developing sustainable collaboration: learning from theory and practice. Prim Health Care Res Develop. 2001;2:139-148.

[134] Linck P, Elliston P, Robinson C, et al. Partnership development framework for interagency working. Bangor: University of Wales; 2002.

[135] Banks P. Partnerships under pressure. London: King's Fund; 2002.

[136] CCF. Partnerships: frameworks for working together U.S: compassion capital fund national resource center; 2009. [cited 2018]. Available from: https://www. strengtheningnonprofits.org/.

[137] Brown C. The Art of coalition building: a guide for community leaders. New York: The American Jewish Committee; 1984.

[138] PMNCH. The partnership for maternal, newborn \& child health in support of every woman every child. strategic plan 2016-2020. Geneva: PMNCH; 2015.

[139] Whitt M. Fighting tobacco: a coalition approach to improving your community's health. Lansing (Michigan): Department of Public Health; 1993.

[140] Sofaer S. Working together, moving ahead: a manual to support effective community health coalitions. New York: City University of New York; 2001.

[141] Rees J, Mullins D, Bovaird T. Partnership working. Birmingham: Third Sector Research Centre, University of Birmingham; 2012.

[142] McQuaid RW. The theory of partnerships - why have partnerships. In: Osborne SP, editor. Managing publicprivate partnerships for public services: an international perspective. London: Routledge; 2000. p. 9-35.

[143] Fawcett SB, Paine-Andrews A, Francisco VT, et al. Using empowerment theory in collaborative partnerships for community health and development. Am J Community Psychol. 1995;23(5):677-697. 
[144] Bennett RJ, McCoshan A. Enterprise and human resource development: local capacity building. London: P. Chapman Pub.; 1993; xiii, 335 p.

[145] Cadbury R. The partnership challenge. Public Policy Review. 1993;1(Nov/Dec):11-12.

[146] Roussos ST, Fawcett SB. A review of collaborative partnerships as a strategy for improving community health. Annu Rev Public Health. 2000;21:369-402.

[147] Cascio WF. Leadership succession: How to avoid a crisis. Ivey Bus J. 2011;75(3):6-8.

[148] Butterfoss FD, Goodman RM, Wandersman A. Community coalitions for prevention and health promotion: factors predicting satisfaction, participation, and planning. Health Educ Q. 1996;23(1):65-79.

[149] Shediac-Rizkallah MC, Bone LR. Planning for the sustainability of community-based health programs: conceptual frameworks and future directions for research, practice and policy. Health Educ Res. 1998;13(1):87108.

[150] Fawcett SB, Lewis RK, Paine-Andrews A, et al. Evaluating community coalitions for prevention of substance abuse: the case of project freedom. Health Educ Behav. 1997;24(6):812-828.

[151] Jones J, Barry MM. Exploring the relationship between synergy and partnership functioning factors in health promotion partnerships. Health Promot Int. 2011;26(4):408-420.

[152] Wolff T. A practitioner's guide to successful coalitions. Am J Community Psychol. 2001;29 (2):173-191. discussion 205-211.

[153] American speech-language-hearing association. Cultural competence; 2018 Apr 11. Available from: www.asha.org/Practice-Portal/Professional-Issues/ Cultural-Competence/. 